Not only may we find here a convenient method of ascertaining absolute configuration, but we may also reap other practical benefit from the ability, which their work presents, of engineering the morphology of crystals.

1. Pateur, L. Ann. Phys. 24, 442 (1848).

2. Bijvoet, J. M., Peerdeman, A. F. \& Bommel, A. J. Van Nature 168, 271 (1951).

3. See, for example, Dunitz, J. D. X-ray Analysis and the Structure of Molecules (Cornell University Press, 1979).

Schmidt, G. M. J. Pure appl. Chem. 27, 647 (1971).

5. Cohen, M. D. \& Green, B. S. Chem. in Britain 9, 490(1973).

6. Thomas, J. M. Phil Trans. R. Soc. A277, 251 (1974); Nature 289, 633 (1981)

Green, B. S., Lahav, M. \& Rabinowich, D. Accts chem. Res. 12, 191 (1979).

\section{C-reactive protein and the acute phase response}

\section{from M. B. Pepys}

ThE acute phase response consists of the increased production of a number of plasma proteins which occurs following most forms of tissue injury, inflammation, infection and malignant neoplasia. C-reactive protein (CRP), so-called because it precipitates pneumococcal somatic $\mathrm{C}$ polysaccharide, was the first 'acute phase protein' to be identified. It was discovered in O.T. Avery's laboratory at the hospital of the Rockefeller Institute and was one of three fundamental contributions to biology to emanate from there, the others being the identification of DNA as the genetic material in pneumococci and the establishment of the role of polysaccharides as antigens.

There has lately been much progress in the characterization of CRP, of other acute phase proteins and the mechanisms underlying the acute phase response in general. These advances were marked recently by the first international meeting* to be held on the subject.

Many circulating proteinase inhibitors, complement, coagulation and transport proteins have been shown to behave as acute phase reactants. The general nature of the acute phase response, its stimulation by many forms of cell injury, and its occurrence in all homoiothermic species, suggest that it fulfills a beneficial function. With respect to CRP this view is supported by the evolutionary conservation of structure and binding reactivity of the CRP

*'C-reactive protein and the plasma protein response to tissue injury', organized by 1 . Kushner, H. Gewurz \& J. E. Volanakis and held at the Barbizon-Plaza Hotel, New York, 21-23 September 1981 under the auspices of the New York Academy of Sciences. Proceedings to be published in the Annals of the Ner. York Academy of Sciences, 1982.

M. B. Pepys is Reader in Immunological Medicine at the Royal Postgraduate Medical School and Honorary Consultant Physician at the Hammersmith Hospital, London. family. CRP of all species binds to phosphorylcholine (PC) residues in the presence of calcium ions and PC-binding proteins homologous with human CRP occur in many vertebrates, including fish, and even in an invertebrate, Limulus polyphemus, the horseshoe crab. A normal human plasma protein, known as serum amyloid $\mathrm{P}$ component (SAP) because the molecule is pentagonal in shape and because it is laid down in amyloid deposits, closely resembles CRP in structure with $60-70$ per cent homology of amino acid sequence. Homologues of human SAP are also present in all vertebrate classes.

A serious pathological complication of a sustained acute phase response, due to persistent infection or inflammation, is the deposition of amyloid A (AA), an extracellular accumulation of protein fibrils consisting of peptide subunits arranged in an anti-parallel $\beta$-pleated sheet. The protein is derived from a serum precursor (SAA) which is an apolipoprotein of high-density lipoprotein produced in the acute phase. The trigger molecule initiating synthesis of SAA and other acute phase proteins by liver cells is apparently interleukin-1 (IL1), a peptide product of macrophages. IL1 also activates $\mathrm{T}$ lymphocytes and is a pyrogen. Its production can be initiated either by direct stimulation of macrophages, for example, with bacterial lipopolysaccharide, or indirectly by mediator(s) released from damaged tissue cells, possibly prostaglandins. The mechanism by which liver cells increase the abundance of mRNA for acute phase proteins in order to provide for their increased synthesis is not yet known. However, the genes for SAA and for $\alpha_{1}$-acid glycoprotein, another acute phase reactant, have now been cloned and this may provide information on control of synthesis as well as on the structure, functions and evolution of the proteins themselves.

The normal in vivo functions of CRP, SAP and SAA are not yet known. Presumably, for CRP and SAP these are related in some way to their strictly conserved ligand-binding properties. CRP binds preferentially to damaged rather than intact autologous cell membranes and having done so, human CRP activates the complement system; part of its role may be to elicit the inflammation required for resolution and repair. CRP also binds to extrinsic ligands and can thus enhance resistance, for example to pneumococcal infection in mice. In addition to being a normal plasma protein and a constituent of amyloid deposits, SAP or a closely related protein is also a normal tissue protein. It is found in glomerular basement membrane and in association with elastic fibre microfibrils throughout the body. Its role in tissues is not known but it is of interest that aggregated SAP selectively binds fibronectin from whole serum.

Clinical measurements of serum CRP, which, like basic studies of CRP itself, suffered a long period of decline, are now being treated with fresh enthusiasm. Such measurements are useful in screening for organic disease and in monitoring the activity of many inflammatory or necrosing disorders, and are a sensitive test for infection. Although the acute phase response is a non-specific manifestation of tissue injury its precise quantification can provide a valuable aid to the clinician at the bedside.

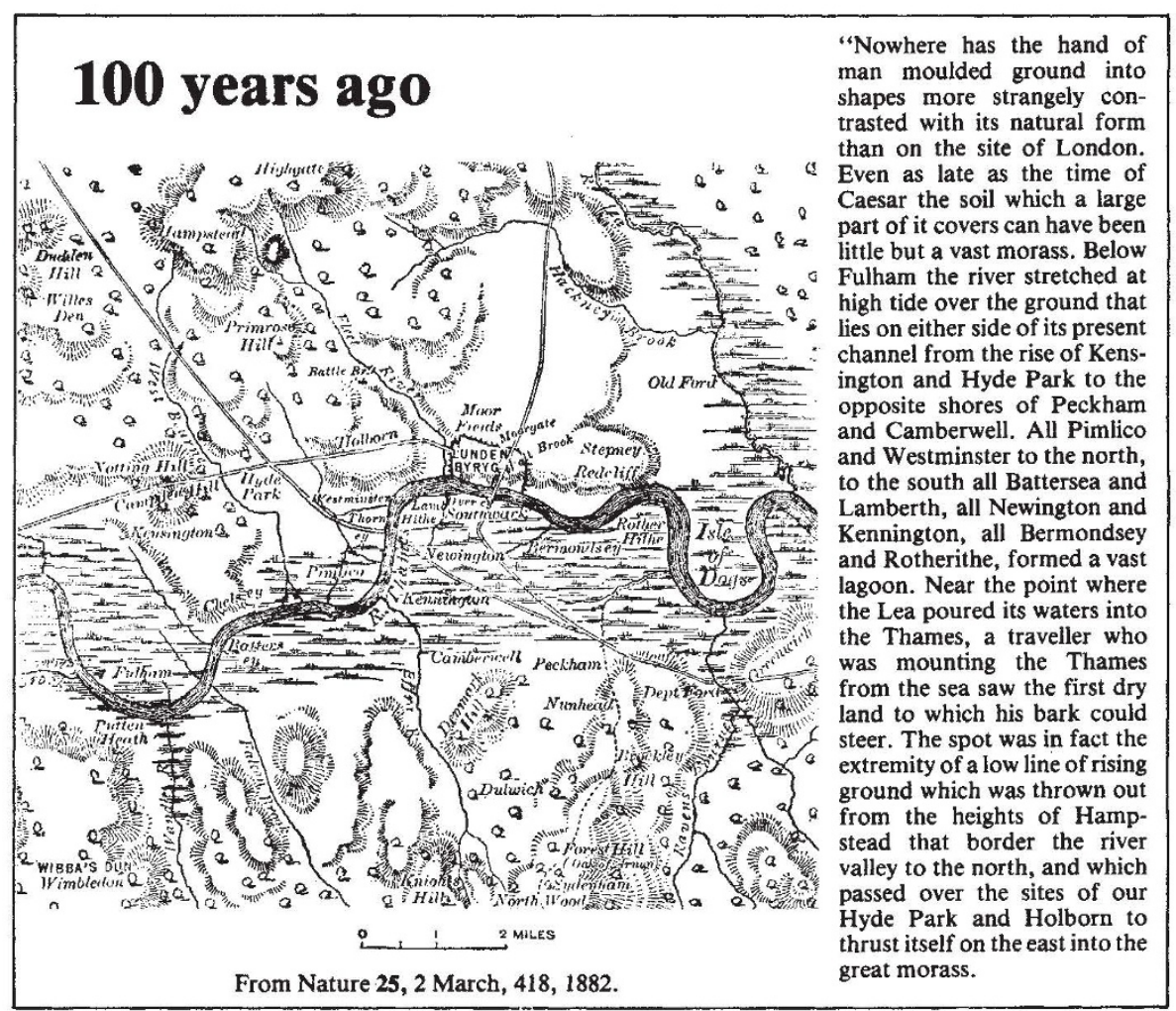

